\title{
Elevada seroprevalencia de citomegalovirus, virus herpes simplex tipo 1 y virus Epstein Barr en adultos con virus de la inmunodeficiencia humana
}

\author{
VIVIAN LUCHSINGER ${ }^{1}$, AMARANTA LUZORO², MARÍA JOSÉ MARTÍNEZ ${ }^{1}$
}

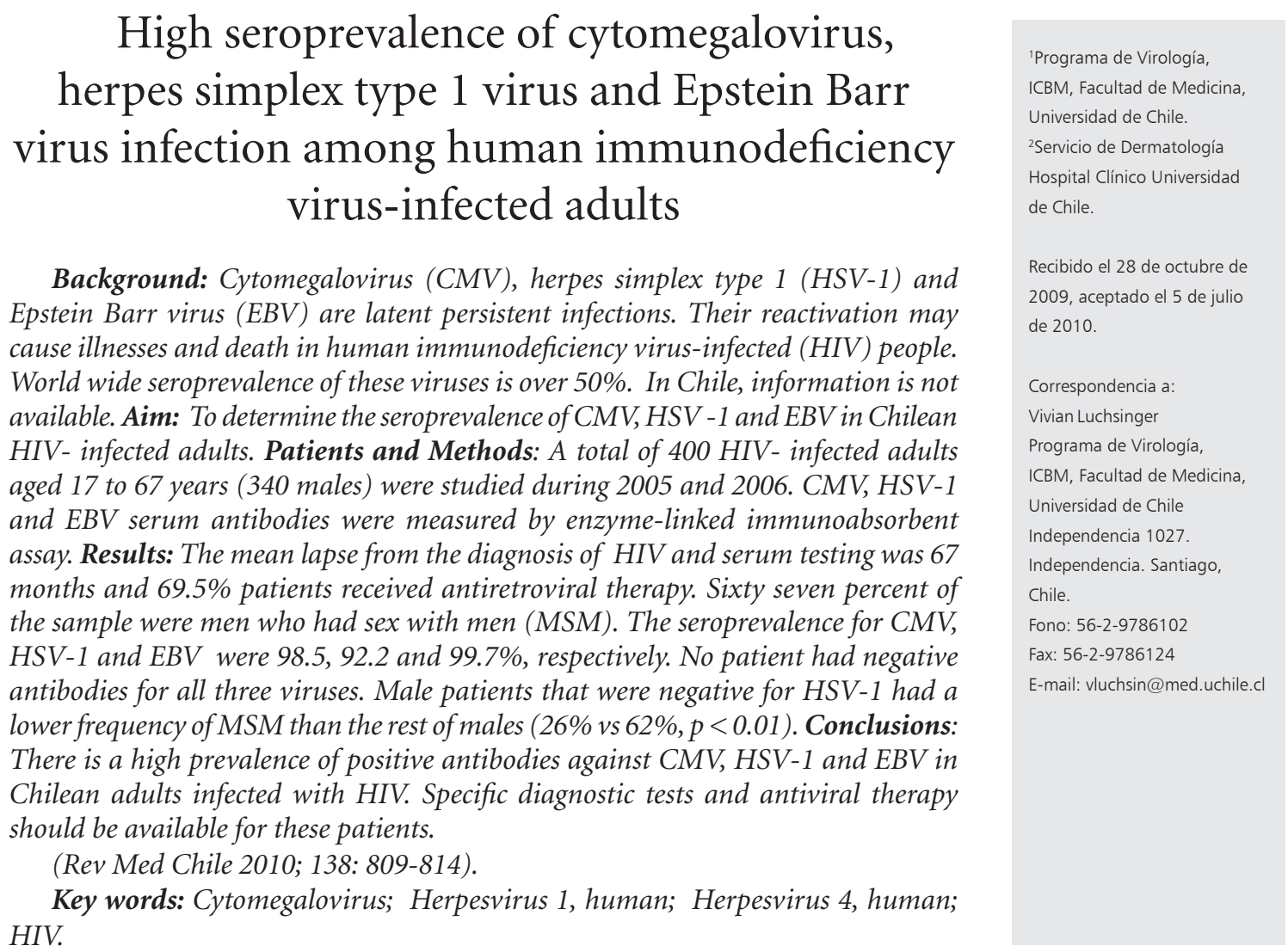

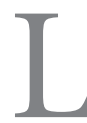
a población de infectados con el virus de la inmunodeficiencia humana (VIH) está en constante aumento. La prevalencia mundial es de $0,8 \%$, en adultos y la incidencia de $2,5 \mathrm{mi}$ llones, estimándose 33,2 millones de infectados ${ }^{1}$. En Chile, más de 17.000 personas están infectadas con VIH o tienen síndrome de inmunodeficiencia adquirida (SIDA), mayoritariamente hombres entre 30 y 39 años, habiéndose notificado 5.288 defunciones hasta $2005^{1}$.

Citomegalovirus (CMV) y los virus herpes simplex tipo 1 (VHS-1) y Epstein Barr (VEB) pertenecen a la familia Herpesviridae. Establecen una infección persistente de por vida en el infectado, pudiendo permanecer en forma latente o en replicación activa. Durante la latencia, el ADN viral se encuentra en el interior del núcleo celular, pero no se detectan partículas virales. Las reactivaciones 
del virus son favorecidas por el compromiso de la respuesta inmune, por lo que son causa frecuente de enfermedad, e incluso muerte, en los inmunocomprometidos ${ }^{2}$.

La seroprevalencia de CMV, VHS-1 y VEB es alta en todo el mundo, especialmente en países en desarrollo y en los grupos de menor nivel socioeconómico ${ }^{2}$. CMV se adquiere a lo largo de toda la vida ${ }^{3}$; VHS-1 generalmente durante la infancia ${ }^{4}$ y VEB habitualmente a temprana edad en países en desarrollo y durante la adolescencia en países desarrollados ${ }^{5}$, infectando a más de $95 \%$ de los adultos. En adultos chilenos, la prevalencia de CMV es superior a $60 \%$ en población general y cercana a $100 \%$ en el nivel socioeconómico menor; la de VHS-1 es $90 \%$, y $76 \%$ la de VEB ${ }^{6-10}$. Estas altas frecuencias se explican por los múltiples mecanismos de transmisión en el caso de CMV - vertical, respiratoria, sexual, parenteral, por trasplante $e^{3}-y$ por la presencia de VEB y VHS-1 en la saliva ${ }^{5,11}$, aún en ausencia de lesiones.

CMV constituye el principal agente de complicación infecciosa en pacientes VIH. Causa retinitis, neumonía, colitis, entre otras, especialmente en pacientes con menos de 50-100 linfocitos $\mathrm{T}$ ayudadores $\mathrm{CD} 4+/ \mathrm{mm}^{3}$. En la era pre terapia antiretroviral (HAART), 40\% de los pacientes $\mathrm{VIH}(+)$ presentaban enfermedad por $\mathrm{CMV}^{3,12}$, disminuyendo a $8 \%$ tras la implementación de este tratamiento.

Los antígenos de membrana permiten diferenciar dos serotipos de virus herpes simplex (VHS-1 y VHS-2). Ambos pueden infectar la mucosa oral y genital. El VHS-2 es una de las infecciones oportunistas más frecuentes en pacientes VIH+ y es la primera causa de úlceras genitales a nivel mundial. En Santiago, Martínez y cols detectaron una seroprevalencia de $77 \%$ en pacientes VIH+ en policlínicos de enfermedades de transmisión sexual (ETS) de las áreas Norte y Sur ${ }^{13}$. El VHS tipo 1 también puede causar infección genital, y aunque recurre con menor frecuencia que el tipo 2 (14-25\% vs $60-88 \%)$ se considera responsable del incremento en el herpes ano-genital, especialmente en hombres que tienen sexo con hombres jóvenes ${ }^{14,15}$.

En pacientes con SIDA, el VEB se asocia con frecuencia a cuadros de úlceras orales y esofágicas ${ }^{16}$ y a enfermedades linfoproliferativas, generalmente de comportamiento agresivo ${ }^{17}$. El linfoma es la segunda causa de neoplasia en estos pacientes y el
VEB se detecta en más de $60 \%$ de estos cuadros, si bien se desconocen los mecanismos virales patogénicos. El linfoma primario del sistema nervioso central (LPSN) afecta a 4 a $6 \%$ de los pacientes con SIDA, constituyendo la segunda causa de lesión cerebral en ellos ${ }^{16,17}$.

En la actualidad se dispone de antivirales eficaces para el tratamiento de la enfermedad por CMV y VHS. El diagnóstico específico permite el manejo oportuno y adecuado de los pacientes con VIH, mejorando su calidad de vida y sobrevida y disminuyendo la propagación del virus. Esto requiere el acceso a las técnicas de laboratorio.

Debido a que en Chile se desconoce la frecuencia de infección por CMV, VHS-1 y VEB en VIH positivos, el objetivo de este estudio fue establecer la seroprevalencia de estos virus en adultos chilenos con VIH.

\section{Material y Método}

Entre octubre de 2005 y noviembre de 2006, se estudiaron 400 pacientes mayores de 17 años VIH positivos, de un universo cercano a 600 que es controlado en el Hospital San José y del cual se excluyeron embarazadas y mujeres en lactancia. Este centro hospitalario atiende a todo el sector público del área Norte de Santiago. Los sueros fueron obtenidos desde muestras de sangre venosa periférica de pacientes voluntarios y mantenidos a $-20^{\circ} \mathrm{C}$ en el laboratorio de Virología. Su utilización fue aprobada por el Comité de Ética de la Facultad de Medicina, Universidad de Chile, en agosto de 2009.

Las características sociodemográficas y de la infección por VIH de los pacientes estudiados fueron obtenidos mediante una encuesta auto resolutiva y registrados en una ficha ad hoc en un estudio previo.

Se realizaron ensayos inmunoenzimáticos específicos para la detección de IgG anti citomegalovirus (Zeus Scientific ${ }^{\circledR}$, USA), anti virus herpes simplex de tipo 1 (HerpeSelect ${ }^{\circledR}$ 1, FOCUS Diagnostics, USA) y anti VCA del virus Epstein Barr (Zeus Scientific ${ }^{\circledR}$, USA), de acuerdo a las instrucciones del proveedor. Se determinó la absorbancia de cada reacción en un espectrofotómetro (Anthos $2001{ }^{\circledR}$ ) con filtro de $450 \mathrm{~nm}$.

Para el análisis estadístico se aplicó la prueba $\mathrm{Z}$ con un nivel de significancia de 5\% con el programa Sigma Stat $3.5^{\circledR}$. 


\section{Resultados}

\section{Características socio-demográficas de la} población estudiada

Los 400 pacientes estudiados eran mayoritariamente del género masculino (85\%), solteros
(64\%) y con educación media o superior $(81 \%)$ (Tabla 1). La mediana de edad fue 38 años y $7,5 \%$ (30/400) era menor de 15 años. El inicio de la actividad sexual en $147 / 400(29,4 \%)$ fue antes de los 15 años, con una mediana de 16 años. El promedio de parejas sexuales referidas en su vida

\section{Tabla 1. Características sociodemográficas y de la infección por VIH de los casos seronegativos para} CMV, VEB y VHS-1 y de la población total

\begin{tabular}{|c|c|c|c|c|c|}
\hline Característica & $\begin{array}{l}\text { CMV } \\
n=5\end{array}$ & $\begin{array}{l}\text { VEB } \\
n=1\end{array}$ & $\begin{array}{l}\text { VHS-1 } \\
n=31\end{array}$ & $\begin{array}{l}\text { Población total } \\
\qquad n=400\end{array}$ & p* \\
\hline $\begin{array}{l}\text { Edad: Mediana } \\
\text { (años) Rango }\end{array}$ & $\begin{array}{c}34 \\
26-41\end{array}$ & 18 & $\begin{array}{r}35 \\
22-61\end{array}$ & $\begin{array}{r}38 \\
17-67\end{array}$ & \\
\hline $\begin{array}{ll}\text { Género: } & \text { Masculino } \\
& \text { Femenino }\end{array}$ & $\begin{array}{l}5 \\
-\end{array}$ & $\begin{array}{l}1 \\
-\end{array}$ & $\begin{array}{r}28(90,3 \%) \\
3(9,7 \%)\end{array}$ & $\begin{array}{l}(85 \%) \\
(15 \%)\end{array}$ & $\begin{array}{l}0,6 \\
0,5\end{array}$ \\
\hline $\begin{array}{l}\text { Estado civil: Casado } \\
\qquad \begin{array}{l}\text { Soltero o Separado } \\
\text { No responde }\end{array}\end{array}$ & $\begin{array}{l}2 \\
2 \\
1\end{array}$ & $\begin{array}{l}- \\
1 \\
-\end{array}$ & $\begin{array}{r}4(12,9 \%) \\
24(77,4 \%) \\
3 \quad(9,7 \%)\end{array}$ & $\begin{array}{rr}103 & (25,75 \%) \\
262 & (65,5 \%) \\
35 & (8,75 \%)\end{array}$ & $\begin{array}{l}0,2 \\
0,3 \\
0,8\end{array}$ \\
\hline $\begin{array}{l}\text { Estudios: Básica } \\
\qquad \begin{array}{l}\text { Media/Superior } \\
\text { No responde }\end{array}\end{array}$ & $\begin{array}{l}1 \\
4 \\
-\end{array}$ & $\begin{array}{l}- \\
1 \\
-\end{array}$ & $\begin{array}{rr}8 & (26 \%) \\
23 & (74 \%) \\
& -\end{array}$ & $\begin{array}{rr}68 & (17 \%) \\
324 & (81 \%) \\
8 & (2 \%)\end{array}$ & $\begin{array}{l}0,3 \\
0,4 \\
0,9\end{array}$ \\
\hline $\begin{array}{c}\text { Inicio actividad sexual (años) } \\
\text { Media } \\
\text { Rango }\end{array}$ & $\begin{array}{c}14 \\
7-33\end{array}$ & 10 & $\begin{array}{r}17 \\
4-33\end{array}$ & $\begin{array}{r}16 \\
4-43\end{array}$ & \\
\hline $\begin{array}{l}\text { Orientación sexual: } \\
\qquad \begin{array}{l}\text { Heterosexual } \\
\text { HSH } \\
\text { No responde }\end{array}\end{array}$ & $\begin{array}{l}3 \\
2\end{array}$ & $\begin{array}{l}- \\
1 \\
-\end{array}$ & $\begin{array}{rr}21 & (68 \%) \\
8 & (26 \%) \\
2 & (6 \%)\end{array}$ & $\begin{array}{rr}122 & (30,5 \%) \\
249 & (62,3 \%) \\
29 & (7,2 \%)\end{array}$ & $\begin{aligned}< & 0,01 \\
< & 0,001 \\
& 0,55\end{aligned}$ \\
\hline $\begin{array}{l}\text { Uso condón: } \\
\qquad \begin{array}{l}\text { Siempre } \\
\text { Ocasional/Nunca }\end{array}\end{array}$ & $\begin{array}{l}2 \\
3\end{array}$ & 1 & $\begin{aligned} 22 & (71 \%) \\
9 & (29 \%)\end{aligned}$ & $\begin{array}{l}(63 \%) \\
(47 \%)\end{array}$ & $\begin{array}{l}0,4 \\
0,08\end{array}$ \\
\hline $\begin{array}{l}\text { Antecedente ETS: } \text { Gonorrea } \\
\text { Condiloma } \\
\text { Sífilis } \\
\text { Herpes genital }\end{array}$ & $\begin{array}{l}- \\
3 \\
1 \\
1\end{array}$ & $\begin{array}{l}1 \\
- \\
- \\
-\end{array}$ & $\begin{array}{rr}2 & (7 \%) \\
15 & (48 \%) \\
8 & (26 \%) \\
5 & (16 \%)\end{array}$ & $\begin{array}{rr}66 & (16,5 \%) \\
156 & (39 \%) \\
108 & (27 \%) \\
64 & (16 \%)\end{array}$ & $\begin{array}{l}0,2 \\
0,4 \\
0,9 \\
0,7\end{array}$ \\
\hline $\begin{array}{cc}\text { Diagnóstico VIH: } & \text { Media } \\
\text { (meses) } & \text { Rango }\end{array}$ & $\begin{array}{c}72 \\
1 \text { a } 120\end{array}$ & 1 & $\begin{array}{r}36 \\
<1-190\end{array}$ & $\begin{array}{r}67 \\
<1-264\end{array}$ & \\
\hline $\begin{aligned} \text { TARV: Sí } & \\
& \text { No } \\
& \text { No responde }\end{aligned}$ & $\begin{array}{l}3 \\
2 \\
-\end{array}$ & $\begin{array}{l}- \\
1 \\
-\end{array}$ & $\begin{aligned} 23 & (74 \%) \\
8 & (26 \%) \\
& -\end{aligned}$ & $\begin{array}{rr}278 & (70 \%) \\
101 & (25,3 \%) \\
21 & (4,7 \%)\end{array}$ & $\begin{array}{l}0,7 \\
0,9 \\
0,4\end{array}$ \\
\hline $\begin{aligned} \text { LTCD4: } & <200 \\
& 200-500 \\
& >500 \\
& \text { No responde }\end{aligned}$ & $\begin{array}{l}1 \\
3 \\
1 \\
-\end{array}$ & $\begin{array}{l}- \\
- \\
1 \\
-\end{array}$ & $\begin{array}{r}10(32,3 \%) \\
12(38,7 \%) \\
8(25,8 \%) \\
1(3,2 \%)\end{array}$ & $\begin{array}{rr}92 & (23 \%) \\
230 & (57,5 \%) \\
64 & (16 \%) \\
14 & (3,5)\end{array}$ & $\begin{array}{l}0,3 \\
0,06 \\
0,2 \\
0,6\end{array}$ \\
\hline
\end{tabular}

Notas: CMV: citomegalovirus; VEB: virus Epstein Barr; VHS-1: virus herpes simplex de tipo 1; VIH: virus de la inmunodeficiencia humana. n: número de individuos. ${ }^{*} p$ mediante prueba Z. HSH: hombre que tiene sexo con hombre. ETS: enfermedad de transmisión sexual. TARV: terapia antirretroviral; LTCD4: linfocitos T CD4 que corresponde al recuento del examen más reciente al momento del registro de los datos. 
fue 24 (rango 1 a 500) y 4 durante el último año. Entre los 249 (62\%) hombres que referían tener sexo con hombres, $54 \%$ se autodefinió como homosexual y $8 \%$ como bisexual. El 64\% (257/400) tenía el antecedente de haber presentado una o más ETS en su vida, siendo condiloma lo más frecuente (39\%).

Aunque el tiempo promedio del diagnóstico de la infección por VIH fue de 67 meses (5,6 años), $25,3 \%$ de los pacientes no recibía terapia antirretroviral (TARV); el recuento promedio de linfocitos CD4+ del examen más reciente fue 347 células $/ \mathrm{mm}^{3}$, con $92(23 \%)$ pacientes con menos de 200 LT CD4+.

\section{Serología}

En 394/400 (98,5\%) pacientes se detectaron anticuerpos anti CMV; 5 fueron negativos y uno indeterminado. El 92,2\% (369) presentó anticuerpos anti VHS-1 y 99,7\% (399) anti VEB. Todos los casos seronegativos correspondieron a diferentes pacientes.

Las características generales de los 31 pacientes seronegativos para VHS-1 fueron similares a las de la población total, excepto en la significativamente menor proporción de HSH (26\% vs $62 \%$, $\mathrm{p}<0,001)$ y en el menor tiempo de diagnóstico de infección por VIH (mediana de 36 meses vs 67 meses) (Tabla 1). El 38,7\% (12/31) inició la actividad sexual antes de los 15 años de vida y 3 de los 31 refirieron más de 2 parejas sexuales en el último año. El $64,5 \%(20 / 31)$ ha presentado una o más ETS.

\section{Discusión}

La seroprevalencia de citomegalovirus (CMV), virus herpes simplex tipo 1 (VHS-1) y virus Epstein Barr (VEB) superior a 90\% en adultos chilenos infectados con VIH detectada en este estudio coincide con lo publicado en otros países ${ }^{2-5,15,18}$ y con la alta frecuencia de estas infecciones en la población chilena general ${ }^{6-10}$.

Esta alta portación de los herpesvirus contribuye a la frecuente participación de estos agentes como causa de enfermedad en la población VIH positiva. A esto se suman las reactivaciones virales favorecidas por el compromiso inmunológico de dichos pacientes, en las cuales el virus se replica y excreta a partir de la latencia que todos los herpesvirus establecen tras la infección primaria. Diferentes estímulos, como radiación ultravioleta, estrés, fiebre, infecciones, pueden desencadenar la replicación viral ${ }^{3}$ desde el ADN latente, ya sea en células del epitelio renal, de glándulas salivales y linfocitos en el caso de CMV; en neuronas ganglionares para VHS-1 y en linfocitos B (LB) para VEB. En inmunocomprometidos las reactivaciones virales generalmente son sintomáticas y de mayor gravedad que en inmunocompetentes ${ }^{2,5}$.

Por todo lo anterior, en pacientes infectados con VIH es necesario sospechar en forma precoz la participación de estos herpesvirus en cuadros clínicos compatibles debiendo incluirse en el diagnóstico diferencial, para lo cual se requiere acceso a técnicas diagnósticas apropiadas. Asimismo, debiera existir la posibilidad de administrar terapia antiviral específica y oportuna en los casos confirmados para optimizar el manejo del cuadro clínico lo que podría, incluso, significar la sobrevida del paciente.

Una consecuencia de la infección concomitante de herpesvirus y VIH es el mayor riesgo de progresión de la infección. Así, CMV participa como cofactor de la progresión a SIDA ${ }^{12,19}$ y la presencia de úlceras genitales determina una mayor contagiosidad del VIH y empeora el curso de la enfermedad, puesto que la disrupción de la barrera mucocutánea produce una migración de linfocitos CD4+ que son susceptibles de infectarse con el VIH. Por esto, el contacto de lesiones producidas por VHS con fluidos genitales con VIH aumenta la probabilidad del contagio viral. Del mismo modo, los pacientes $\mathrm{VIH}+$ que presentan una coinfección con VHS serán más contagiantes que los VHS negativos. Estudios recientes están orientados a evaluar el número de nuevos casos de infección por VIH que podrían haber sido evitados solamente con el manejo adecuado del $\mathrm{VHS}^{20}$, por lo que conocer la condición de susceptibilidad frente a este agente permitiría enfatizar las estrategias de prevención de la adquisición de estas infecciones, como el uso de condón ${ }^{21}$.

Si bien la alta portación de los herpesvirus sugiere considerar infectado a todo paciente VIH positivo, $7 \%$ de susceptibles a VHS-1 detectada en este estudio plantea la necesidad de establecer esta condición entre los adultos con VIH, con el fin de enfatizar dirigidamente las estrategias de prevención de la infección a quienes están en riesgo de primoinfectarse por este virus. La identificación de 
factores de riesgo respecto a la infección herpética podría contribuir a sospechar un posible susceptible. Al respecto, la única diferencia entre seronegativos e infectados por VHS-1 detectada en nuestro estudio fue la significativa menor proporción de hombres que tienen sexo con hombres. Aunque en Chile $70 \%$ de las primoinfecciones y $90 \%$ de las recurrencias de herpes genital son causadas por el virus herpes simplex de tipo $2^{22}$, igualmente el tipo 1 puede ser transmitido por vía sexual, adquiriendo cada vez más importancia en este sentido y en el desarrollo del herpes anal ${ }^{14}$. Por esto es llamativo que los seronegativos para VHS-1 detectados en este estudio permanezcan en esta condición pese a presentar conductas de riesgo como el inicio precoz de la actividad sexual (mediana 17 años), el no uso o en forma ocasional de preservativos en un tercio de ellos y la presencia de alguna ETS en la mitad de estos pacientes. Es posible que esta aparente contradicción se explique por la significativa menor proporción de hombres que tienen sexo con hombres entre los seronegativos lo que podría indicar la importancia del tipo de actividad sexual en la transmisión viral, lo que debiera ser considerado para enfatizar las estrategias de prevención de la infección. Estudios posteriores podrán determinar si el VHS-1 está adquiriendo mayor importancia en nuestra población.

Respecto a CMV y VEB, no fue posible analizar factores de riesgo de infección debido a la alta seroprevalencia detectada. Probablemente la juventud del paciente (18 años) sea la explicación del único caso seronegativo para VEB, situación que debiera revertir en el tiempo a medida que se vaya exponiendo a personas excretoras, como ocurre en casi toda la población chilena. Esta exposición precoz probablemente explique la ausencia de diferencias en la edad entre los seronegativos para VHS-1 y la población total estudiada.

En conclusión, debido a la alta frecuencia de infección y de causa de enfermedad e, incluso de mortalidad, de los herpesvirus en población chilena infectada con VIH es necesario establecer algoritmos de estudio en pacientes con sospecha clínica de enfermedad por algunos de estos agentes, y disponer de acceso a técnicas diagnósticas y a terapia antiviral específica con el fin de mejorar su sobrevivencia y calidad de vida en nuestro país.

Agradecimientos: A Cristian Moreno por su valioso apoyo técnico.

\section{Referencias}

1. García M, Olea A. Evolución y situación epidemiológica de la infección por virus de inmunodeficiencia humana y síndrome de inmunodeficiencia adquirida en Chile. Rev Chil Infectol 2008; 25 (3): 162-70.

2. Kaplan JE, Benson C, Holmes KH, Brooks JT, Pau A, Masur $\mathrm{H}$ et al. Guidelines for prevention and treatment of opportunistic infections in HIV-infected adults and adolescents: recommendations from CDC, the National Institutes of Health, and the HIV Medicine Association of the Infectious Diseases Society of America MMWR Recomm Rep 2009; 58 (RR-4): 1-207.

3. Monto H. The history of cytomegalovirus and its diseases. Med Microbiol Immunol 2008; 197: 65-73.

4. Tunbäck P, Bergstöm T, Claesson B, Carlsson R, Löwhagen $\mathrm{G}$. Early acquisition of herpes simplex virus type 1 antibodies in children - A longitudinal serological study. J ClinVirol 2007; 40: 26-30.

5. Kutok JL, Wang F. Spectrum of Epstein-Barr virus- associated diseases. Ann Rev Pathol Mech Dis 2006; 1 : 375-404.

6. Contreras MC, Escaff V, Salinas P, Saavedra T, Suárez M. Detección de marcadores virales y parasitarios en adolescentes embarazadas y sus recién nacidos en reisgo. Rev Chil Obstet Ginecol 1995; 60 (2): 85-9.

7. Suárez M, Briones $H$, Luchsinger V, Schultz R, Peña M, De Diego S, et al. Primoinfección por citomegalovirus en embarazadas de diferente condición socioeconómica. Rev Med Chile 1994; 122: 1153-7.

8. Luchsinger V, Suárez M, Montiel F, Kaltwasser G. Evolución de la infección por citomegalovirus en trasplantados renales. Rev Med Chile 1999; 127: 9-17.

9. Abarca K, Vial P, Zamorano J, Paris C, Ferres M, Villarroel L, et al. Seroprevalencia de citomegalovirus y Toxoplasma gondii em menores de 30 años en Santiago, Chile. Rev Med Chil 1997; 125 (5): 531-8.

10. Ferres M, Prado P, Ovalle J, Fuentes R, Villarroel L, Ferrecio C, et al. Seroprevalencia de infección por virus Epstein Barr en población sana de Santiago de Chile. Rev Med Chile 1995; 123 (12): 1447-52.

11. Arduino P, Porter S. Herpes simplex virus type I infection: overview on relevant clinico-pathological features. Rev J Oral Pathol Med 2008; 37: 107-21.

12. Steininger C, Puchhammer-Stöckl E, Popow-Kraupp T. Cytomegalovirus disease in the era of highly active antiretroviral therapy (HAART). J Clin Virol 2006; 37 (1): 1-9.

13. Martínez MJ, Navarrete N, Santander E, Garmendia ML, Gubelin W. Seroprevalence of herpes simplex virus type 2 (HSV-2) infection in two clinics for sexually transmit- 
ted diseases in Santiago, Chile. Rev Med Chile 2005; 133 (3): 302-6.

14. Ryder N, Jin F, McNulty AM, Grulich AE, Donovan B. Increasing role of herpes simplex virus type-1 in first episode anogenital herpes in heterosexual women and younger men who have sex with men. 1992-2006. Sex Transm Infect 2009.

15. Smit C, Pfrommer C, Mindel A, Taylor J, Spaargaren J, Berkhout B, et al. Rise in seroprevalence of herpes simplex virus type 1 among highly sexual active homosexual men an increasing association between herpes simplex virus type 2 and HIV over time (1984-2003). Eur J Epidemiol 2007; 22 (12): 937-44.

16. Syrjanen S, Leimola-Virtanen R. Oral ulcers in AIDS patients frequently associated with cytomegalovirus and Epstein-Barr virus infections. J Oral Pathol Med 1999; 28: 204-9.

17. Rezk S, Weiss L. Epstein- Barr virus- associated lymphoproliferative disorders. Hum Pathol 2007; 38: 1293 -
1304.

18. Russell D, Tabrizi S, Russell J, Garland S. Seroprevalence of herpes simplex types 1 and 2 in HIV-infected and uninfected homosexual men in a primary care setting. J Clin Virol 2001; 22 (3): 305-13.

19. Griffiths P. CMV as a cofactor enhancing progression of AIDS. J Clin Virol 2006; 35: 489-92.

20. Celum CL. The interaction between herpes simplex virus and human immunodeficiency virus. Herpes 2004; 11 (1): 36A-45A.

21. Carré N, Robain M, Dussaix E, Salmon- Ceron D, Meyer L. Sexual factors associated with cytomegalovirus seropositivity in human immunodeficiency virus- infected men. The Seroco Study Group. Sex Transm Dis 1997; 24 (19): 582-6.

22. Súarez M, Labbé V, Saavedra T. Tipos Víricos del Herpes Simple asociados a infecciones genitales primarias y recurrentes en Chile. Bol Oficina Sanit Panam 1988; 105: 13-9. 